\title{
Health complications of female genital mutilation in Sierra Leone
}

This article was published in the following Dove Press journal:

International Journal of Women's Health

5 July 2012

Number of times this article has been viewed

\section{Owolabi Bjälkander \\ Laurel Bangura ${ }^{2}$ \\ Bailah Leigh ${ }^{3}$ \\ Vanja Berggren' \\ Staffan Bergström' \\ Lars Almroth'}

'Division of Global Health, Department of Public Health, Karolinska Institutet, Stockholm, Sweden; ${ }^{2}$ Inter Africa Committee, Sierra Leone; ${ }^{3}$ Department of Community Health, College of Medicine and Allied Health Sciences, University of Sierra Leone, Sierra Leone
Correspondence: Owolabi Bjälkander Division of Global Health, Department of Public Health, Karolinska Institutet, Nobels väg 9, SE-I7I 77 Stockholm, Sweden

$\mathrm{Tel}+46738$ I7I 638

Fax +4685248311509

Email owolabi.bjalkander@ki.se
Abstract: Sierra Leone has one of the highest rates of female genital mutilation (FGM) in the world, and yet little is known about the health consequences of the practice.

Purpose: To explore whether and what kind of FGM-related health complications girls and women in Sierra Leone experience, and to elucidate their health care-seeking behaviors.

Patients and methods: A feasibility study was conducted to test and refine questionnaires and methods used for this study. Thereafter, a cross-section of girls and women $(n=258)$ attending antenatal care and Well Women Clinics in Bo Town, Bo District, in the southern region and in Makeni Town, Bombali District, in the northern region of Sierra Leone were randomly selected. Participants answered interview-administrated pretested structured questionnaires with open-ended-questions, administrated by trained female personnel.

Results: All respondents had undergone FGM, most between 10 and 14 years of age. Complications were reported by 218 respondents $(84.5 \%)$, the most common ones being excessive bleeding, delay in or incomplete healing, and tenderness. Fever was significantly more often reported by girls who had undergone FGM before 10 years of age compared with those who had undergone the procedure later. Out of those who reported complications, 187 (85.8\%) sought treatment, with 89 of them visiting a traditional healer, 75 a Sowei (traditional circumciser), and 16 a health professional.

Conclusion: The high prevalence rate of FGM and the proportion of medical complications show that FGM is a matter for public health concern in Sierra Leone. Girls who undergo FGM before 10 years of age seem to be more vulnerable to serious complications than those who are older at the time of FGM. It is important that health care personnel are aware of, and look for possible complications from FGM, and encourage girls and women to seek medical care for their problems.

Keywords: female genital cutting, female circumcision, health consequences, age at FGM, treatment seeking, caregiver

\section{Introduction}

Female genital mutilation (FGM) refers to procedures that intentionally alter or cause injury to the female genital organs for nonmedical reasons. ${ }^{1}$ Estimates are that between 100 million and 140 million girls and women have undergone FGM and that 3 million girls in Africa are at risk annually. ${ }^{2,3}$ Although the practice originates from, and continues to be practiced in, 28 countries in Africa, it has also been found in Asia and parts of the Middle East. ${ }^{1}$

Many reasons are given for why FGM occurs, the perceived reason being that it is a cultural and traditional practice. The reason for FGM has been linked to religious, obligatory rites, even though there is no written requirement for FGM in any of the 
holy books. ${ }^{4}$ Some communities believe that the reduction of a woman's sexual drive is a virtue often associated with sexual morality. Through FGM, the clitoris is removed in the belief that this will ensure the woman's "decent behavior." 5 As the practice is often linked with social acceptance, it is practiced as a social convention that carries its own rewards and punishments, the latter being a reason for continuing the practice. Girls and their families might face peer pressure, rejection, or stigmatization if they do not participate in this practice, and may feel that the social benefits of the practice (identification, access to resources, and opportunities for marriage) outweigh the disadvantage of harm on the girl. ${ }^{6}$ The persistence of the practice is nevertheless propelled by interrelated sociocultural factors, these varying within regions, countries, and ethnic groups within the same country.

In some communities like in Sierra Leone, FGM takes place as part of an initiation ceremony that is a recognized rite of passage for girls into women, recognizing that she has been correctly raised and is ready for marriage. ${ }^{7}$ In this context, girls are rewarded with celebrations, gifts, and public recognition. ${ }^{8}$

\section{Types of FGM and classification}

The term "female genital mutilation" continues to be used by the World Health Organization (WHO) to recognize potentially physical harm caused by the act, even though the intention of the act is not to cause mutilation. ${ }^{1}$ The practice has been classified into four types, as can be seen in Table 1. Type I describes the partial or total removal of the clitoris, and Type II describes partial or total removal of the clitoris and the labia minora. The placement of the labia minora and or the labia majora so that they come into contact is described by Type III, and Type IV is the category for other harmful procedures to the female genitalia for nonmedical purposes, such as elongation of the labia majora, piercing or pricking the clitoris, and scraping the inner walls of the vaginal passage. ${ }^{1}$

\section{Nomenclature}

A variety of terms exist to describe the practice of removal (whether partial or total) or alteration of the external female genitalia.

Practicing communities use a variety of names to describe the practice, and local groups working with these communities tend to use the name in the local language. The term "female circumcision" is the translation in English for the practice from many of the African languages. The term "circumcision" can be seen as problematic, as it might cause female
Table I The World Health Organization classification of female genital mutilation

Complete typology with subdivisions:

- Type I - partial or total removal of the clitoris and/or the prepuce (clitoridectomy).

- When it is important to distinguish between the major variations of type I mutilation, the following subdivisions are proposed: type la, removal of the clitoral hood or prepuce only; type lb, removal of the clitoris with the prepuce.

- Type II - partial or total removal of the clitoris and the labia minora, with or without excision of the labia majora (excision).

- When it is important to distinguish between the major variations that have been documented, the following subdivisions are proposed: type lla, removal of the labia minora only; type llb, partial or total removal of the clitoris and the labia minora; type llc, partial or total removal of the clitoris, the labia minora, and the labia majora.

- Note also that, in French, the term "excision" is often used as a general term covering all types of female genital mutilation.

- Type III - narrowing of the vaginal orifice with creation of a covering seal by cutting and appositioning the labia minora and/or the labia majora, with or without excision of the clitoris (infibulation).

- Type Illa, removal and apposition of the labia minora; Type IIlb, removal and apposition of the labia majora.

- Type IV - all other harmful procedures to the female genitalia for nonmedical purposes, eg, pricking, piercing, incising, scraping, and cauterization.

Reproduced with permission from World Health Organization. Eliminating female genital mutilation: an interagency statement (UNAIDS, UNDP, UNECA, UNESCO, UNFPA, UNHCR, UNHCHR, UNICEF, UNIFEM, WHO); 2008.'

and male circumcision to be seen as anatomically similar. The circumcision of boys involves the removal of the foreskin, or prepuce, from the penis. This act is performed for reasons of religion, for culturally imposed concepts of hygiene, or for aesthetic reasons. However, the extent of cutting in what is commonly referred to as "female circumcision" is anatomically more extensive than in male circumcision. Rahman and Toubia $^{9}$ describes that, anatomically, the male equivalent of clitoridectomy performed on females would be the amputation of most of the penis, and that the male equivalent of infibulation of females would be the removal of all of the penis, its roots of soft tissue, and part of the scrotal skin.

When discussion about the practice began in the 1980s in the global arena, the focus changed from traditional and cultural practices to women's reproductive health and rights, and this brought new terms to describe the practice.

The term "female genital mutilation" was used in the Programme of Action adopted by the International Conference on Population and Development (Cairo, 1994), and the practice was seen as a "basic human rights violation," urging governments to stop the practice wherever it exists.

Most United Nations documents use the term "female genital mutilation" in order to recognize the potentially severe 
physical harm that can be caused by the act. In 1990, the Inter-Africa Committee on Traditional Practices Affecting the Health of Women and Children formally adopted the term "female genital mutilation", and reinforced this decision at its general assembly meeting in April 2005.

As the term "female genital mutilation" has been found to be offensive or shocking to women and communities who do not consider the practice a mutilation, many organizations working with communities refer to the act as "female genital cutting" as a more value-neutral, nonjudgmental, sensitive, and respectful term. However, some argue that the term "cutting" does not cover all forms of FGM, as in the case of when there is appositioning, the suturing or bringing of the two sides of the labia majora together. ${ }^{1}$

The term "female genital mutilation" is used in this study because it is the term adopted by the WHO, and the research questions in this study aim to identify the existence and types of health complications girls and women experience due to the act of removal of external female genitalia.

\section{Health complications as a result of FGM}

Previous studies have shown that the type/severity of FGM is related to the nature of the morbidity experienced in the short and long term. According to the WHO, some of the harm and known physical complications caused by the removal of, and damage to, healthy, normal female genital tissue in the short term include severe pain, shock, excessive bleeding, difficulty in passing urine, and infections. ${ }^{1}$ In the long term, all types of FGM, but particularly infibulation, have been found to be associated with reproductive health morbidities, increased risk of childbirth complications, infertility, and cervical cancer. ${ }^{10-14}$ For many of the longterm sequelae, findings refer to populations where the type of FGM practiced is usually Type III, infibulation, which is unlikely to apply to the Sierra Leonean population, where Types I and II FGM are believed to predominate.

\section{Sierra Leone}

Sierra Leone is on the west coast of Africa, surrounded by Guinea and Liberia and bordered by the Atlantic Ocean (Figure 1). The area of Sierra Leone was once a colony and protectorate governed by the British Empire from the 1780s. Sierra Leone gained independence from the UK in 1961. The country has twelve districts plus the Western Area, which includes Freetown, the capital, and the villages on the Peninsula.

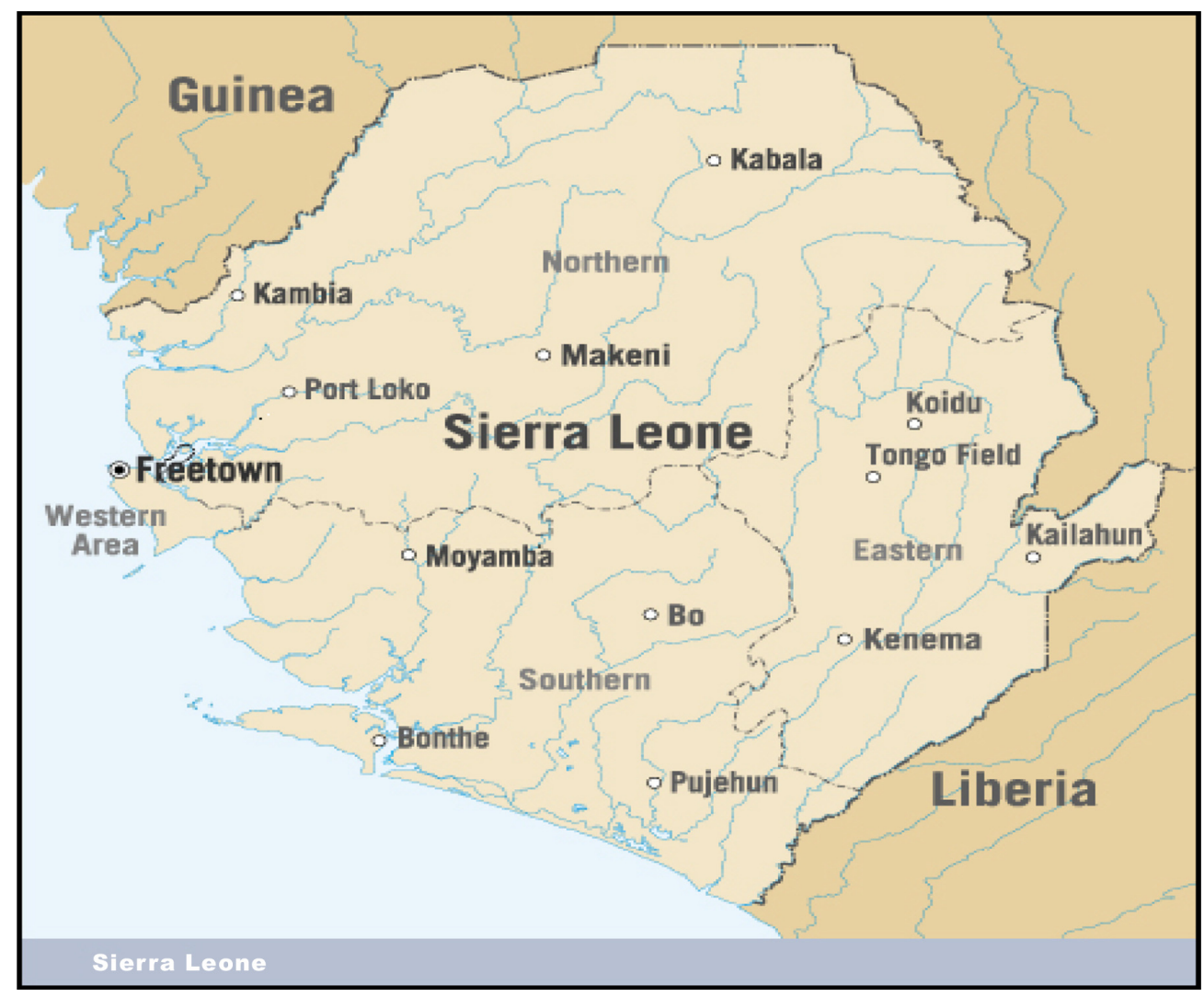

Figure I Sierra Leone with its main districts, cities, and neighboring countries. 
With a population of approximately 6 million people, there are 13 main ethnic groups in Sierra Leone, each with its own language, and a total of some 20 ethnic groups altogether. ${ }^{15}$ The largest groups are the Mende in the southern region, and the Limba and Temne in the northern region. These groups make up approximately $90 \%$ of the population. The city Freetown is inhabited by the Krio - an original mixture of freed slaves from the UK, the US, Nova Scotia, and the Caribbean. Krio is the language spoken by the Krio peoples in Freetown, the Peninsula, Banana, York, and Bonthe Islands. Krio is also the lingua franca in the country.

It has also been difficult to give precise estimates on the religious makeup of the country, because people move easily between one religious belief and another. Some sections of the population identify themselves with one main religion when asked about their faith, and also practice another set of religious and traditional beliefs. Nevertheless, it has been estimated that most people practice Islam (60\%), with $30 \%$ of the population practicing indigenous religions and $10 \%$ practicing Christianity. ${ }^{16}$

\section{FGM and the initiation ceremony}

FGM in Sierra Leone takes place as part of an initiation ceremony, which identifies a woman as belonging to a particular ethnic group and through which the community recognizes when a girl becomes a woman.

This initiation ceremony also gives membership to a women-only led and run secret society called Bondo. ${ }^{17}$

The initiation ceremony takes place over several weeks where the girls and women are secluded in a clearing several kilometers away from the nearest village, and consists of various activities. This clearing, surrounded by palm leaves, is referred to as the Bondo Bush.

The women who are the heads of the society are also the traditional excisors. Their local names depend on the ethnic group, as Table 2 shows, but are generally referred to as Soweis. Soweis are usually older women who are feared and respected as women with supernatural powers. The role of a Sowei is hereditary.
The first activity in the initiation ceremony is FGM. While the girls heal they are taught what their roles are in the family, in the community, and to other women who belong to the Bondo society.

After the period of seclusion, the girls, now Bondo members, and recognized women in their communities, are led back in procession and dance to the village to be welcomed by their families with gifts and festivities.

It is not known why FGM is part of the initiation ceremony. Some say the physical pain involved in the procedure helps to create a life-long friendship fellowship among those girls who were initiated together. One of the reasons given for Bondo initiation is that it prepares a girl for marriage, and therefore sexual activity. The reason for the practice can be seen as different from the reasons for FGM in Eastern Africa, where FGM is believed to protect the single girl from premarital sex and the married woman from extramarital sex. ${ }^{18}$

The practice of FGM in the aspect of preparing a girl for marriage, family, and community responsibilities is similar to the reasons for FGM in, for instance, Tanzania. As in Sierra Leone, it is a rite of passage for girls into womanhood, and women can face social stigma if they have not undergone FGM. This is different from Kenya, where as well as a rite of passage for girls, FGM continues also because of the belief that it can control women's sexuality and is a necessary tradition. ${ }^{1}$

In spite of the high prevalence of FGM in Sierra Leone, there is little knowledge on the negative health effects of the practice and possible implications for health care. The cultural complexity of the practice of FGM might explain why there is still a lack of research on FGM and related health complication in Sierra Leone.

To our knowledge, there has been only one study on the health consequences of FGM amongst women in Sierra Leone. Published by Koso-Thomas ${ }^{17}$ in 1985, this study covered 300 participants in the Western Area region of Sierra Leone, and women reported pain and hemorrhage regardless of the type of FGM that was performed.

Table 2 Names of aspects of Bondo society in the main Sierra Leonean languages

\begin{tabular}{lllll}
\hline $\begin{array}{l}\text { Ethnic } \\
\text { group }\end{array}$ & $\begin{array}{l}\text { Name of } \\
\text { Bondo society }\end{array}$ & $\begin{array}{l}\text { Name of head } \\
\text { of society/bush }\end{array}$ & Name of & Name of \\
Fulah & Baytee & Barajelli & Betijor & noninitiate \\
\hline Limba & Bondo & Baregba & Gbonka & Jiwor \\
Loko & Bondona & Ligba & Bondona/Bondofayra & Gboroka \\
Mende & Sande & Sokonday/Sowei/Majo & Sandewi & Gborrga \\
Susu & Guhngiri & Joangojeri & Taysingeh & Pkowei \\
Temne & Bondo & Digba & Aboanka & Amoogaangeh \\
\hline
\end{tabular}


The aim of our study was to determine whether and which kind of health complications girls and women in Sierra Leone experience during and after FGM, and to examine associated health care-seeking behaviors.

Although being an initiate was not an inclusion criterion for this study, questions about health complications and treatment-seeking behaviors were asked only of those women who had been initiated.

\section{Material and methods}

\section{Setting}

The location of the study was in two districts in Sierra Leone: Bo in the Southern Province, with a population of approximately 152,000 women, and Bombali in the Northern Province, with a population of 169,000 women. ${ }^{15}$

The clinics were situated in locations that can be described as urban or periurban. The urban clinics were those located in the town capitals of the districts. In Bo town (the capital town for the Bo District), these were the Government Hospital and clinics owned by Marie Stopes Sierra Leone and Planned Parenthood Association of Sierra Leone. In Makeni town (the capital town for Bombali District), the Government Primary Health Care Center at Masuba, Red Cross, and Loreto private hospitals were used.

The periurban clinics were those situated in rural settings that could be reached within 2 hours by foot. In Bombali District, there were community health centers and health posts in Binkolo, Fula Town, Kolisoko, Makama, Makolo, Makump, Mangay Loko, Mapaki, Masingbi Lul, Masori, Masuba, Panlap, Puntung, and Robat.

\section{Methods}

This was a clinic-based study of girls and women attending women's health clinics that provided sexual and reproductive health services. The inclusion criteria were girls and women in the age range 10-49 years. Interview-administered faceto-face semistructured questionnaires were used to collect the data.

Each questionnaire took approximately 20 minutes to complete. Data were collected over a 7-month period in 2006.

Ethical permission was sought and obtained from the Ethics Board in Sierra Leone. The Sierra Leone Ethics Board recommended that the questionnaires should be administered by a female health professional who was respected in the community and who had herself joined the Bondo society - whether she was an active member or not. As a result, the instrument was administered by data collectors who were health professionals from the following cadres: maternal and child health aides, State-enrolled community health nurses, and State-registered nurses. Supervisors were nursing sisters, and project oversight and coordination was provided by the district medical officer.

The questionnaires were administered in Mende or Krio in Bo District and Temne or Krio in Bombali District, Krio being the lingua franca spoken in most parts of the country. Responses were written down in English because the local languages are primarily oral and are not widely written down and read.

\section{Development and testing of research tool}

The questionnaire was developed based on a previous data collection instrument that had been used in the Sudan. ${ }^{19}$

The questionnaires were tested in the different types of health facilities in the different districts amongst a population of girls and women attending health care facilities during sessions specifically for women, as described previously.

One of the modifications made to the questionnaire was that questions did not refer to female circumcision or FGM. Given that FGM occurs only within the initiation ceremony in these parts of Sierra Leone, and that posing a question that directly asked about female circumcision could be interpreted by the respondents as "wanting to know about the secrets of society," participants were asked whether they had been initiated into the Bondo society. ${ }^{20}$ An affirmative response to this question was taken as a proxy measurement of a positive FGM status.

First, participants were asked "Have you been to the Bondo Bush?". Then, participants were asked "Did you experience any health problems from initiation?". If the answer was yes, then participants were asked to describe the nature of the health problem they attribute to the initiation.

The data collectors during the feasibility study mentioned that they were sometimes called to the Bondo Bush to treat complications such as infections, excessive bleeding, or fever. We then decided that questions about the nature of health problems girls and women had experienced during initiation should be open-ended so that the respondents themselves could describe the health problems they attribute to initiation, to avoid being led by the interviewer in any direction.

Thus, the complications responses recorded are those the respondents mentioned spontaneously, which the data collectors then filled in on the list of complications they had on the questionnaire. 
Participants were then asked "Did you seek medical care because of this health problem?" If the answer was yes, then participants were asked "Who provided the care?"

Independent variables consisted of age (summarized in 5-year age groups), religion (Christianity, Islam, none), educational status (attended school, did not attend school), occupation, and ethnicity.

\section{The data collection process}

At each data collection site, the first participant was randomly selected and then every fifth girl/woman afterwards.

Participants were approached by the data collector and were provided with information about the survey.

The data collector explained that participation in the survey was optional and would not affect the standard of care the respondent would receive, nor would it lead to any increased risk.

Respondents were also told that the information they provided would remain confidential, and that anonymity would be respected as the data would be analyzed summarily.

Respondents were also informed that that they could withdraw from the survey at any time. Respondents were not given any incentive for participating in the study.

Respondents were included after having given their oral informed consent, and the data collector signed the questionnaire to indicate consent.

In total, 300 participants were selected and, of these, 258 decided to participate in the study. $\chi^{2}$ was used to analyze differences between proportions, and a $P$-value below 0.05 was considered significant.

\section{Results}

There are complete answers on questions about FGM for 258 respondents, but for questions concerning sociodemographic characteristics, there are complete answers for only $154(59.7 \%)$ respondents (Table 3 ), as the data collectors did not consistently record all the elements of the sociodemographic details.

The respondents were mainly young women in their twenties, more from urban than rural settings. Two-thirds had attended school or were at school, many finishing at the secondary school level. The majority of participants described themselves as economically active, and the main occupations were farmers, traders, and housewives. These jobs are not usually within the measured higher quintiles of wealth. All respondents reported that they had been initiated into the Bondo society.
Table 3 Sociodemographic characteristics of the study population

\begin{tabular}{|c|c|c|}
\hline Sociodemographic variables & Numbers & Percentage (\%) \\
\hline \multicolumn{3}{|l|}{ Age (years) } \\
\hline $11-15$ & 18 & 11.7 \\
\hline $16-20$ & 45 & 29.2 \\
\hline $21-25$ & 39 & 25.3 \\
\hline $26-30$ & 17 & 11.0 \\
\hline $31-35$ & 20 & 13.1 \\
\hline $36-40$ & 10 & 6.5 \\
\hline $4 I-45$ & 5 & 3.2 \\
\hline Total & 154 & 100 \\
\hline \multicolumn{3}{|l|}{ Religion } \\
\hline Christianity & 72 & 46.8 \\
\hline Islam & 81 & 52.6 \\
\hline None & 1 & 0.6 \\
\hline Total & 154 & 100 \\
\hline \multicolumn{3}{|l|}{ Educational status } \\
\hline Attended school & 102 & 66.2 \\
\hline Only primary education & 39 & \\
\hline Only secondary education & 55 & \\
\hline Only tertiary education & 8 & \\
\hline Did not attend school & 52 & 33.8 \\
\hline Total & 154 & 100 \\
\hline \multicolumn{3}{|l|}{ Occupation } \\
\hline Employed & 130 & 84.4 \\
\hline Unemployed & 24 & 15.6 \\
\hline Total & 154 & 100 \\
\hline \multicolumn{3}{|l|}{ Ethnic group } \\
\hline Temne & 47 & 30.5 \\
\hline Limba & 40 & 26 \\
\hline Mende & 32 & 20.8 \\
\hline Fulah & 7 & 4.5 \\
\hline Loko & 11 & 7.2 \\
\hline Susu & 4 & 2.7 \\
\hline Kono & 5 & 3.2 \\
\hline Korankoh & 5 & 3.2 \\
\hline Madingo & 3 & 1.9 \\
\hline Total & 154 & 100 \\
\hline
\end{tabular}

In this sample, most girls had undergone FGM between the ages of 10 and 14 years $(43.4 \%, n=112)$, with $23.7 \%$ $(n=61)$ between 0 and 9 years, and 26.7\% $(n=69)$ at an age of 15 years and over (Table 4). The same table displays the age at FGM found in other studies as well, for comparison.

The majority $(84.5 \%, \mathrm{n}=218)$ of respondents reported complications to FGM. Thirty-one (12\%) said they had no problems after FGM, and nine respondents (3.5\%) did not know (Figure 2). The proportion of positive responses to complications is highest for the 10-15 year age range when FGM was performed, and an equally and unexpectedly high proportion of girls who did not know when FGM was performed reported that they experienced complications (Figure 2). 
Table 4 Age at female genital mutilation for the present study population and Demographic and Health Surveys (DHS) in Sierra Leone $(\mathrm{SL})$ and neighboring countries

\begin{tabular}{|c|c|c|c|c|c|c|c|c|}
\hline Age (years) & Infant & $0-1$ & $2-4$ & $5-9$ & $10-14$ & $15+$ & Do not know & Total \\
\hline $\begin{array}{l}\text { This population - only those } \\
\text { with sociodemographic data }\end{array}$ & 0 & $\mathrm{I}(0.7)$ & II (7.I) & $28(18.2)$ & $64(41.6)$ & $39(25.3)$ & II (7.I) & $154(100)$ \\
\hline $\begin{array}{l}\text { The whole present study } \\
\text { population }\end{array}$ & 0 & 0 & $18(7.0)$ & $43(16.7)$ & II 2 (43.4) & $69(26.7)$ & $16(6.2)$ & $258(100)$ \\
\hline SL DHS 2008 (\%) & 22.2 & 0.1 & 0.9 & 13.0 & 35.6 & 19.1 & 9.1 & \\
\hline Senegal DHS 2005 (\%) & 59.6 & 3.7 & 9.5 & 14.9 & 5.1 & 0.9 & 6.3 & \\
\hline Guinea DHS 2005 (\%) & 33.7 & 0.1 & 1.9 & 31.5 & 26.5 & 3.1 & 3.2 & \\
\hline Mali DHS 2006 (\%) & 57.0 & 4.6 & 6.5 & 17.0 & 8.2 & 1.1 & 5.6 & \\
\hline Cote d'Ivoire DHS 200 I (\%) & $55(0-4)$ & & & $14(5-8)$ & $\begin{array}{l}11.4(9-10) \\
5.5(11-12)\end{array}$ & 8.1 & & \\
\hline Nigeria DHS 2008 (\%) & $\begin{array}{l}82.4 \\
\text { (under I year) }\end{array}$ & & $1.6(1-4)$ & $12.5(5+)$ & & & & \\
\hline
\end{tabular}

Note: Percentages in parentheses.

Of the 1057 FGM-related complications reported, excessive bleeding $(78.4 \%, \mathrm{n}=171)$, delay in, or incomplete, healing $(68.3 \%, n=149)$, and tenderness $(62.8 \%, n=137)$ were the most common. Interestingly, 100 respondents ( $45.9 \%$ of all who had undergone FGM) reported they suffered fever, suggesting a more severe infection. Tenderness is described as discomfort or pain felt when pressure is applied to the part.

Table 5 provides the type of complications reported in two categories of age at which FGM was performed: before or during the respondent's 10th year, and after the respondent's 10th year. The results show that $41 \%$ of respondents who underwent FGM before or during their 10th year reported fever, compared with $24.1 \%$ of girls who underwent FGM after their 10 th year $(P<0.03)$.

Out of the 218 who reported complications, 187 (85.8\%) further reported that they sought treatment for these complications. Most sought treatment from a traditional healer $(47.6 \%, n=89)$, a Sowei $(40.1 \%, n=75)$, or a nurse $(8.6 \%$, $\mathrm{n}=16$ ). A traditional healer is one who uses knowledge, skills, and practices indigenous to his/her cultures to diagnose, treat, and improve physical and mental health. ${ }^{21}$

Table 6 shows the proportions of girls in two categories of age at FGM: those who underwent FGM before their 10th birthday, and those who underwent FGM on or after their 10 th birthday. These proportions are distributed by the type

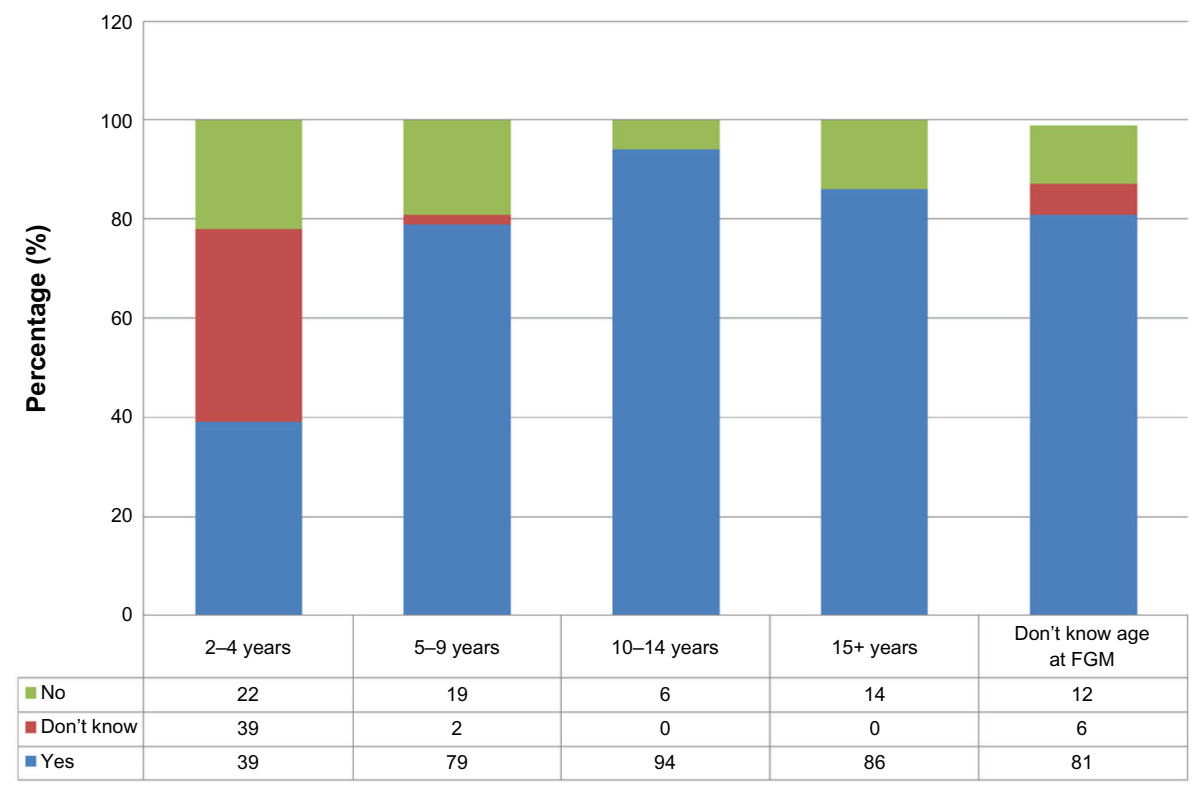

Figure 2 Complication responses by age at female genital mutilation. 
Table 5 Different types of complications reported by age at female genital mutilation (FGM) by two categories: $\leq 10$ years and $>10$ years of age (respondents who did not know their age are excluded)

\begin{tabular}{|c|c|c|c|}
\hline \multirow[t]{2}{*}{ Complication } & \multicolumn{2}{|c|}{ Age at FGM (years) (\%) } & \multirow[t]{2}{*}{$P$-value } \\
\hline & $\leq 10(n=59)$ & $>10(n=84)$ & \\
\hline Shock & $4(6.9)$ & $38(43.7)$ & $<0.01$ \\
\hline Bleeding & $25(43)$ & $42(48.3)$ & 0.37 \\
\hline Fever & $24(4 \mid .4)$ & $21(24.1)$ & $<0.05$ \\
\hline Urine retention & $8(13.8)$ & $19(21.8)$ & 0.17 \\
\hline Fainting & $14(24.1)$ & $23(26.4)$ & 0.62 \\
\hline Swelling & $18(3 \mid)$ & $52(59.8)$ & $<0.01$ \\
\hline Tears & $12(20.7)$ & $23(26.4)$ & 0.33 \\
\hline Wound & $32(55.2)$ & $4 I(47 . I)$ & 0.52 \\
\hline Wound infection & $7(12.1)$ & $16(18.4)$ & 0.25 \\
\hline
\end{tabular}

of caregiver visited for treatment. We see that more respondents who underwent FGM before their 10th birthday and had complications were treated by a Sowei $(52.9 \%)$, and more respondents who underwent FGM after their 10th birthday were treated by a traditional healer $(53.1 \%)$.

\section{Discussion}

This study shows that girls and women in Sierra Leone often experience complications following FGM and that medical complications most often do not come to the attention of medically trained people. The results were based on what girls and women reported they experienced during and after FGM, and which they themselves attributed to the procedure of genital cutting.

As these results were not based on clinical findings by health professionals, it is difficult to judge the actual severity of the complications. The problems reported were, however, considered severe enough for these girls and women to seek treatment for them. Another limitation with this study is that because findings are based on what clinical attendees report, the sample is not representative, and the most disabling and fatal complications may have been excluded. It is quite obvious from the answers that the focus is on immediate or short-term complications.

Long-term effects can sometimes be difficult to relate to FGM for the one who is affected. It is likely that recall bias influenced the reports of complications from early childhood, which may have resulted in under-reporting of complications in this study. In spite of these limitations, the findings give an interesting picture of the magnitude of complications of FGM and from where girls and women seek treatment for these problems.

There are complete sociodemographic data only on 154 $(59.7 \%)$ out of 258 respondents. This is because some data collectors left out these questions when the clinics were busy. The other parts of the questionnaire are filled out correctly. The group for which we do not have sociodemographic data is very similar to the rest of the respondents, as can be seen in Table 4. Thus, there does not seem to be any systematic error in data collection influencing the results as a whole.

The original intention for this study was that the data collectors could perform genital inspections in order to get an anatomic description of the external genitalia from respondents. Girls and women we found during the feasibility study were not able to report on the extent of cutting or give a description of the external genitalia. It was apparent, however, during the training period and in the time available that it was not possible to train the data collectors to consistently and accurately describe what they saw, so this task was abandoned and questions relating to anatomic descriptions were dropped from the questionnaire. Genital inspection was not performed in the present study, making it impossible to relate the extent of FGM performed to complications reported.

Concerning FGM status, in this study, all the girls and women (aged 11-45 years) had undergone FGM, compared with the Sierra Leone Demographic and Health Survey 2008 (SL DHS 2008), where it is reported that $91.3 \%$ of girls and women between the ages of 15 and 49 years had undergone FGM. ${ }^{16}$ The SL DHS 2008 covers more areas in the country and also ethnic groups known to not practise FGM, such as the Christian Krios, which explains the difference. In Sierra Leone it is usually the mother, the grandmother, or another female member of the family who decides whether and when a girl will be initiated. ${ }^{8,17}$

This study showed a different age at FGM compared with previous findings. Although all respondents had undergone

Table 6 Type of caregiver distributed by category of age at female genital mutilation (FGM) - frequency (percentages in parentheses)

\begin{tabular}{lllll}
\hline & Sowei* & Nurse/sister & Traditional birth & $\begin{array}{l}\text { Traditional } \\
\text { attendants }\end{array}$ \\
\hline Age at FGM $<10$ years $(n=34)$ & $18(52.9)$ & $5(14.7)$ & $1(2.9)$ & $10(29.4)$ \\
Age at FGM $\geq 10$ years $(n=146)$ & $56(38)$ & $8(5.4)$ & $4(2.7)$ & $78(53.1)$ \\
\hline
\end{tabular}

Note: *Although the $\chi^{2}$ test gave a $P$-value of 0.05 , this result should be treated with caution, as low numbers used in the statistical calculation make the results unreliable. 
FGM, 10-14 years is the most common age range in which FGM was performed in this sample (43.4\%) compared with the SL DHS 2008 population (35.6\%). There are indications from both this study and the SL DHS 2008 findings that the age at which FGM is performed is lower than the expected age range of early puberty. In our study, almost one out of four $(23.7 \%)$ underwent FGM before their 10th birthday, and in the SL DHS 2008 population 36.2\%. These proportions may be higher in this study if it is assumed that respondents who said they do not know when FGM was performed were too young to remember.

\section{Complications and their reporting}

A surprisingly high number of complications of FGM emerged in this study. This high proportion of complications reported was unexpected, given the secrecy that typically surrounds the practice of FGM in general, and the taboos associated with the initiation ceremony of the Bondo society specifically. The specially trained female data collectors, all initiates to the Bondo, seem to have administered the questionnaires in an empathetic way, which made the respondents willing to share their experiences. The proportion reporting complications in this study is much higher than in a study in the Gambia (where like Sierra Leone Type I and Type II predominate), which still recorded high percentages of complications, especially infections. Immediate complications were reported among $23.7 \%$ respondents who had experienced Type I FGM, 55\% respondents who had experienced Type II FGM, and 19\% respondents who had experienced Type III FGM. ${ }^{22}$

Previous studies have suggested that FGM contributes significantly to the morbidity of girls, most of whom tend not to be treated in hospital settings. ${ }^{23,24}$ There might be several reasons that may account for why, in Sierra Leone, FGM-related complications tend not to be treated in hospital settings.

Firstly, the location of the Bondo Bush - where the initiation ceremony for becoming a member of the society usually takes place - tends to be some kilometers away from the village or nearest town where health facilities are likely to exist, so this distance may give rise to a delay in getting a girl to hospital. It is probable the girl will have to be carried, if she is unable to walk.

Secondly, the Soweis - the heads of the Bondo Bush and traditional circumcisers - are often skilled in the use of medicinal herbs and other treatments. We suspect that the Sowei is more likely to first provide treatment for complication, and this will introduce another kind of delay in seeking treatment in a hospital setting.
Other studies in clinical settings show under-reporting of complications from FGM, and this may be not only because of the sensitivities described previously but also because not all women (or parents of girls) would likely attribute complications to FGM. A study in pediatric surgery unit in Benin City, Nigeria, that examined the complications and patterns of presentation due to FGM reported that parents were likely to believe that complications were due to unseen, spiritual forces rather than to FGM. ${ }^{23}$ Such beliefs are also common in Sierra Leone. ${ }^{17,25}$

It is possible also that the socioeconomic character of families who seek health treatment in a hospital/clinical setting is different from those who seek health treatment elsewhere. FGM-related complications may not report at hospitals, as families would have to pay for treatment, and this might be seen as too costly.

There have been reports on deaths attributed to FGM, eg, from tetanus in Nigeria, a country where Types I and II FGM also predominate, as is believed to be practiced in Sierra Leone. ${ }^{17}$ In Sierra Leone, however, it is difficult to determine the number of girls and women who die from FGM-related complications, as such deaths may be attributed to "spirits" instead.

\section{Types of complications reported}

Our study found excessive bleeding, delay in wound healing, and tenderness as the most common types of complications reported. To our knowledge, there is only one previous report on complications of FGM in Sierra Leone, by Koso-Thomas in $1987 .{ }^{17}$ In that particular study, almost all women reported pain, and about half reported hemorrhage as a result of FGM. About one third of the respondents had developed prolapses, but the study was based in a clinic and there was no control group, so it is not possible to draw any conclusion on the association between FGM and prolapses. Our findings are similar to those of a study in the Gambia, where immediate complications were characterized by infections, hemorrhage, and anemia when FGM was performed. ${ }^{22}$

Our results are different from a study in a Benin City surgery among Edo people in Nigeria that found clitoridal cyst formation, hemorrhage from clitoridal arteries, and labial adhesion as the most frequent complications. ${ }^{23}$ Similarly, in a hospital-based study in south-east Nigeria, inclusion clitoral dermoid cyst and labial fusion were reported as complications amongst girls aged $1-5$ years on whom FGM had been performed between 8 and 90 days after birth. ${ }^{24}$ It is obvious that study design and setting affect what kind of complications are found. 
There seems to be a difference in type of complications in different age groups. The results show that fever is significantly more often reported amongst those girls who underwent FGM in the $0-10$ year age group. This difference may be because fever after the FGM is more common in prepubertal girls than in adolescent girls, indicating a higher risk of infections. Before puberty there is no local protective environment in the vulva, as is the case after the hormonal changes of puberty. Thus, the prepubertal vulva is more sensitive to infections, and infections may ascend to the internal genital organs, causing pelvic inflammatory disease. In fact, there is reason to believe that sequelae of childhood genital infections following FGM are risk factors for infertility in young women. ${ }^{13}$

Two other complications - shock and tenderness - also show statistically significant difference between the different age groups, but there is, as far as we know, no logical explanation for this. Recall bias may have influenced the reporting of these complications.

The design of this study does not allow us to determine the severity of the complication or the severity in relation to age, given that we were not able to perform genital inspections, and that respondents had not attended hospital/clinic as a direct result of injury due to FGM. Serious complications from FGM among young girls have, as previously mentioned, been reported from Nigeria. ${ }^{24}$ In our study, for girls who were very young when FGM was performed but for whom complications were reported, we suspect that they were told what happened to them during or immediately after FGM rather than them remembering the experience themselves. The fact that fever seems to be more common as a result of FGM in the lower age group does, however, indicate that prepubertal girls are more vulnerable to serious complications compared with girls who undergo FGM later.

\section{Health care-seeking behaviors}

Results from this study provide some insight into the health treatment-seeking behaviors of girls and women who experience complications from FGM. Over $80 \%$ of the respondents sought health treatment from the Sowei or a traditional healer, less than $10 \%$ from a nurse, and none from a doctor. This confirms discussions with the health practitioners who administered the questionnaire that they tend to get to know of FGM-related injury only when they are called into the Bondo Bush on an emergency basis. There seems to be little evidence that health practitioners are being approached to perform FGM on girls outside of the Bondo Bush setting, the type of medicalization of the practice that tends to take place in some East African countries such as Kenya, Djibouti, and Ethiopia, ${ }^{26}$ and in Asian countries such as Indonesia. ${ }^{27}$

It is not clear why more girls who underwent FGM under the age of 10 years sought treatment from a Sowei, whereas those who underwent FGM over the age of 10 years sought treatment from a traditional healer. One explanation might be that the younger children are more carefully watched by the Soweis while the Bondo Bush is in session. They are possibly more likely to be examined, rather than to be asked how they feel and whether they are experiencing any problems. With the older girls, if they do not verbally report any problems, they are not examined, and are possibly more likely to take any complications "home" with them to the villages after the initiation and after the Bondo Bush has been dismantled. Should these complications not heal as they ought, these girls then resort to the traditional healer in the village, not the Sowei, because that person is near at hand.

Further studies in Sierra Leone on the use of the clinical setting for health treatment of FGM could include questions on the length of delay between injury and treatment. Delay in seeking health care is likely to add to the severity of the complication. Families present at hospital with more lifethreatening complications often after they have tried and failed with traditional treatments, these having occurred over months, with the traditional healer urging patience. ${ }^{23}$ It would have been interesting to know how many respondents had first visited a traditional healer before resorting to a health facility.

\section{Conclusion}

FGM affects almost all women in Sierra Leone, and from the results of this study it appears that a high proportion of women who undergo FGM suffer from complications that need treatment at the moment of the ritual. It seems that younger girls are more vulnerable to serious complications than those who have reached puberty.

Given the high proportions of reported complications in this study, health education messages about FGM could be disseminated to, inter alia, encourage individuals to seek health treatment quickly and from health professionals for FGM-related complications.

FGM merits more attention in research and policy in Sierra Leone. The effects the practice might be having on the life of young girls and women must be examined more closely. Even if a majority of women face problems due to FGM that they need to seek care for, very few consult trained 
health professionals. It would be important to understand and establish how the health care system can gain people's confidence to treat complications.

\section{Disclosure}

The authors report no conflicts of interest in this work.

\section{References}

1. WHO Press, World Health Organisation, Geneva, Switzerland. Available from: http://www.who.int/reproductivehealth/publications/ fgm/9789241596442/en/index.html. Accessed June 13, 2012.

2. Yoder PS, Abderrahim N, Zhuzhun A. Female Genital Cutting in the Demographic and Health Surveys: A Critical and Comparative Analysis. Calverton, Maryland: Macro International Inc; 2004.

3. Yoder PS, Khan S. Numbers of Women Circumcised in Africa: The Production of a Total. Calverton, Maryland: Macro International Inc; 2007.

4. World Health Organization, United Nations Population Fund (WHO, UNFPA). Towards the elimination of female genital mutilation: a training manual for the affected countries in the Eastern Mediterranean Region. Cairo, World Health Organization Regional Office for the Eastern Mediterranean; 2006.

5. END FGM - European campaign. Ending female genital mutilation, a strategy for the European Union institutions, executive summary. Brussels, END FGM - European Campaign). Available from: http:// www.endfgm.eu/content/assets/END_FGM_Final_Strategy_Summary. pdf. Accessed May 1, 2012.

6. United Nations Children's Fund (UNICEF). Female genital mutilation/ female genital cutting: a statistical report; 2005. Available at http://www. unicef.org/publications/files/FGM-C_final_10_October.pdf. Accessed 29 May 2012.

7. Ahmadu F. Rites and wrongs: an insider/outsider reflects on power and excision. In: Shell-Duncan B, Hernlund Y, editors. Female "Circumcision" in Africa: Culture, Controversy and Change. Boulder, CO: Lynne Rienner; 2000:283-312.

8. Behrendt A. Female genital cutting in the Moyamba and Bombali Districts of Sierra Leone. Dakar, Sierra Leone: Plan West Africa Regional Office; Dec 2005.

9. Rahman A, Toubia N. Female Genital Mutilation. A Practical Guide to Worldwide Laws and Policies. London, UK: Zed Books; 2000.

10. Morison L, Scherf C, Ekpo G, et al. The long-term reproductive health consequences of female genital cutting in rural Gambia: a communitybased survey. Trop Med Int Health. 2001;6(8):643-653.

11. Jones H, Diop N, Askew I, Kaboré I. Female genital cutting practices in Burkina Faso and Mali and their negative health outcomes. Stud Fam Plann. 1999;30(3):219-230.

12. WHO study group on female genital mutilation and obstetric outcome. Female genital mutilation and obstetric outcome: WHO collaborative prospective study in six African countries. Lancet. 2006;367(9525): 1835-1841.
13. Almroth L, Elmusharaf S, El Hadi N, et al. Primary infertility after genital mutilation in girlhood in Sudan: a case control study, Lancet. 2005;366(9483): 385-391.

14. Ibrahim A, Rasch V, Pukkala E, Aro AR. Cervical cancer risk factors and feasibility of visual inspection with acetic acid screening in Sudan. Int J Womens Health. 2011;3(6):117-122.

15. Statistics Sierra Leone. Final results. 2004 Population and Housing Census. 2006. Available from: http://www.sierra-leone.org/Census/ ssl_final_results.pdf. Accessed March 21, 2012.

16. Statistics Sierra Leone (SSL) and ICF Macro. 2009. Sierra Leone Demographic and Health Survey 2008. Calverton, MD: Statistics Sierra Leone (SSL) and ICF Macro. Available from: http://www.measuredhs. com/pubs/pdf/FR225/FR225.pdf. Accessed March 21, 2012.

17. Koso-Thomas O. Circumcision of Women: A strategy for Eradication. London, UK: Zed Books; 1987.

18. World Health Organization. Men's and Women's Perceptions of the Relationship between Female Genital Mutilation and Women's Sexuality in Three Communities in Egypt. Geneva, Switzerland: World Health Organization; 2010.

19. Almroth L, Almroth-Berggren V, Hassanein OM, et al. A community based study on the change of practice of female genital mutilation in a Sudanese village. Int J Gynaecol Obstet. 2001;74:179-185.

20. Sipsma HL, Chen PG, Ofori-Atta A, Ilozumba U, Karford K, Brandleya EH. Female genital cutting: current practices and beliefs in western Africa. Bull World Health Organ. 2012;90:120-127.

21. World Bank. Traditional healer services. Available from: http://web. worldbank.org/WBSITE/EXTERNAL/TOPICS/EXTHEALTHNU TRITIONANDPOPULATION/EXTHSD/0,,contentMDK:20190826 $\sim$ menuPK:438812 pagePK:148956 piPK:216618 theSitePK:37679 3,00.html. Accessed May 1, 2012.

22. Kaplan A, Hechavarría S, Martín M, Bonhoure I. Health consequences of female genital mutilation/cutting in the Gambia, evidence into Action. Reproductive Health. 2011;8:26.

23. Osarumwese Osifo D, Evbuomwan I. Female genital mutilation among Edo people: the complications and pattern of presentation at a pediatric surgery unit, Benin City. Afr J Reprod Health, 2009;13(1): $17-25$.

24. Ekenze SO, Ezegwui HE, Adiri CO. Genital lesions complicating female genital cutting in infancy: a hospital-based study in south-east Nigeria. Ann Trop Paediatr. 2007;27:285-290.

25. Kallon I, Dundes L. The cultural context of the Sierra Leonean Mende woman as patient. $J$ Transcult Nurs. 2010;21(3):228-236.

26. United Nations Population Fund (UNFPA), New York, USA;2010.

27. IRIN News. Female genital mutilation persists despite ban. Available from: http://www.irinnews.org/Report/90366/INDONESIA-Femalegenital-mutilation-persists-despite-ban. Accessed May 15, 2012.
International Journal of Women's Health

\section{Publish your work in this journal}

The International Journal of Women's Health is an international, peerreviewed open-access journal publishing original research, reports, reviews and commentaries on all aspects of women's healthcare including gynecology, obstetrics, and breast cancer. Subject areas include Chronic conditions (migraine headaches, arthritis, osteoporosis);

\section{Dovepress}

Endocrine and autoimmune syndromes; Sexual and reproductive health; Psychological and psychosocial conditions. The manuscript management system is completely online and includes a very quick and fair peer-review system. Visit http://www.dovepress.com/ testimonials.php to read real quotes from published authors. 